\title{
Viaje a un mito de autor a través de los géneros en El muerto y ser feliz (Javier Rebollo 2012)
}

Luis García-Torvisco

Gonzaga University

garcia-torvisco@gonzaga.edu

\begin{abstract}
At a time when the concept of auteur cinema is being deeply questioned, the cinematographic work of Spanish director Javier Rebollo (1969-) can be understood as a sample of formal characteristics and experimental narratives leading to a reaffirmation of director as an auteur. In Rebollo's third film, El muerto y ser feliz (The Dead Man and Being Happy 2012), Santos, a dying hitman, goes on a journey from Buenos Aires to Northern Argentina that progressively acquires a symbolic meaning, as it is a journey from civilization to nature, from life to death, and, ultimately, from history to myth. The physical decline of Santos and his overcoming of physical death-and of linear timethrough his transformation in myth, is parallel to a deconstruction of traditional cinematic language in the movie. Through a meta-reflective articulation of the road movie genre and through the distancing effect caused by the existence
\end{abstract}


of two narrators who, competing with each other, simultaneously construct and deconstruct Santos' story with their ironic and polysemic words, Rebollo attempts to reaffirm his position as a director-auteur, as the sole creator of an auteur myth ("mito de autor") versus the traditional myth, oral and collective by nature.

Keywords: Javier Rebollo; El muerto y ser feliz; myth; auteur cinema; road movie; orality

\section{Resumen}

En un momento de profundo cuestionamiento del concepto de cine de autor, la obra cinematográfica de Javier Rebollo (1969-) se puede entender como un muestrario de características formales y narrativas experimentales conducentes a una reafirmación del director como auteur. En su tercera película El muerto y ser feliz (2012), Santos, un moribundo asesino a sueldo, inicia un viaje de Buenos Aires al norte de Argentina que adquiere progresivamente un marcado carácter simbólico al ser un viaje de la civilización a la naturaleza, de la vida a la muerte, y, fundamentalmente, de la historia al mito. La creciente decadencia física del protagonista y la "superación" de su muerte-y del tiempo lineal -, a través de su eternización en mito es paralela a la deconstrucción del lenguaje cinematográfico convencional en un intento de crear una retórica de la imagen cinematográfica desnaturalizada y basada en la contradicción y el sentido múltiple, especialmente en la articulación meta-reflexiva de géneros como el de la road movie y en el extrañamiento que produce la existencia de dos narradores en off que con su irónica palabra van construyendo y destruyendo, a veces simultáneamente, la historia de Santos. Detrás de esa puesta en escena de la creación discursiva de un mito a partir de la multiplicidad de referentes genéricos y voces narrativas se encuentra siempre, sin embargo, su director. En ese sentido, el proceso de mitificación de Santos a partir de una palabra plural y polisémica en El muerto y ser feliz se puede entender, paradójicamente, como un intento de reafirmar la autoridad de Rebollo como director-autor, como creador de un mito de autor frente al mito tradicional, oral y colectivo por naturaleza. 
Palabras clave: Javier Rebollo; El muerto y ser feliz; mito; cine de autor; road movie; oralidad

Inventar el regreso del mundo

después de su desaparición.

E inventar un regreso a ese mundo

desde nuestra desaparición.

Y reunir las dos memorias,

para juntar todos los detalles.

Hay que ponerle pruebas al infinito,

para ver si resiste.

(Roberto Juarroz, “112”, Séptima Poesía Vertical)

esde su popularización a partir de los años 50, el concepto de cine de autor- "la politique des auteurs" o "auteur theory" en sus principales encarnaciones-ha sido frecuentemente cuestionado por no tener en cuenta el carácter colectivo de la creación cinematográfica o por minimizar la importancia de este trabajo en favor del director como auteur. Este cuestionamiento de la idea romántica de un director creador, idea que, según Timothy Corrigan, probablemente fue siempre un mito (101-36), se ha intensificado en las últimas décadas con los profundos cambios en los mecanismos de producción, distribución, comercialización y exhibición del producto cinematográfico (Jordan y Allinson 72) como consecuencia de los avances tecnológicos, la introducción de nuevas técnicas de producción digitales y el desarrollo de las plataformas de streaming. Para dar cuenta de estos cambios y de cómo han afectado nuestra apreciación de qué significa ser un director autor en un mundo cada vez más globalizado, en los últimos años se han introducido conceptos como el de "autor mediático" (Triana- 
Toribio) o el de "autor global", caracterizados por darle un mayor énfasis al contexto industrial y cultural de la producción cinematográfica (Davies 3) para asi dar cuenta de las maneras "in which film directors, old and new, capture the zeitgeist in a multi-layered world, overtly or covertly" (Jeong y Szaniawski 1). Paradójicamente, esta necesidad de adaptación muestra la vigencia de un concepto, que, pese a haber sido declarado obsoleto por diversas escuelas críticas, ha resurgido una y otra vez (Jeong y Szaniawski 1), especialmente en la crítica especializada y en el aparato institucional de las cinematografías nacionales, así como en las constantes reivindicaciones, frecuentemente relacionadas con la petición de subvenciones gubernamentales, por parte de productores y directores tradicionalmente asociados con él. Harto significativas son, en este sentido, las palabras que el director Pedro Almodóvar (1949-) le dirigió al presidente del Gobierno español en su discurso de aceptación del Goya 2020 a mejor dirección: "Me gustaría decirle, sin que le moleste porque está como invitado, que el cine de autor e independiente que se hace fuera de los márgenes de televisiones y plataformas está en serias vías de extinción y necesita la protección, no ya de su Gobierno, sino del Estado" ("Goya.Almodóvar, mejor dirección").

A pesar de contar con una larga tradición de cine de género, los cines nacionales europeos todavía se siguen asociando, sobre todo en el circuito de festivales y en el mercado internacional, con un cine de autor, perpetuándose la idea de que las películas más representativas de las cinematografías de Europa son aquellas en que el director, con frecuencia también guionista, controla los aspectos más importantes de la producción, lo que le permite expresar su visión única como autor, visión que, además, se puede rastrear, en términos de continuidades y discontinuidades, a lo largo de toda su obra en términos temáticos y, sobre todo, formales. La cinematografía española no es, en este sentido, una excepción, pues “[t]he Spanish critical corpus-reviewers and writers for journals such as Dirigido por and more recently, Cahiers du 
cinéma: España-still frequently use the director as a pivot on which to base discussion on Spanish cinema" (Davies 3), mientras que, internacionalmente, el cine español, aunque mayoritariamente de género, todavía "tends to be located and promoted as part of a wider category of European 'foreignlanguage' cinema... and [it is] presented to mainly art-house audiences as a predominantly auteurist-led cinema as opposed to the generically driven, industrially-based production of Hollywood" (Jordan y Allinson 73).

En este contexto, después de la profunda renovación que tuvo lugar en la cinematografía española en la década de los noventa del siglo pasado, en los últimos quince años ha aparecido una serie de nuevos directores a los que la crítica no ha dudado en incluir en la tradición de autor del cine español. En ese sentido, en la última edición de la canónica Historia del cine español de la editorial Cátedra, escrita por algunos de los más importantes historiadores de la cinematografía española, se dice: "A partir de 2004 se ha consolidado la carrera de algunos nuevos directores portadores de una mirada claramente diferenciada" (Gubern et al.). Esta "mirada claramente diferenciada" es uno de los eufemismos usados frecuentemente para referirse a la obra "personal" de directores autores alejada en mayor o menor medida de las constricciones narrativas y formales de lo que Burch identificó como el "modo de representación institucional cinematográfico" (M.R.I.), asociado con el cine clásico de Hollywood, un cine industrial de entretenimiento caracterizado por construir un universo verosímil y autosuficiente, con una narrativa "que avanza siguiendo una lógica casual y progresiva" mediante un montaje invisible que garantiza la continuidad entre planos y que borra toda huella enunciativa (“Modo de representación"). En este grupo de nuevos directores se puede incluir, entre otros, a Jaime Rosales (1970-), Isaki Lacuesta (1975-), Aitor Arregi (1977-), Jon Garaño (1974-) y José María Goenaga (1976-), Fernando Franco (1976-) o, más recientemente, a Paula Ortiz (1979-), Jonás Trueba (1981-), Carlos Marqués-Marcet (1983-) y Carla Simón (1986-). Entre ellos, destaca 
también Javier Rebollo (1969-), cuya obra cinematográfica se compone hasta el momento de, varios cortometrajes y proyectos documentales para televisión, así como de tres películas (Lo que sé de Lola [2006], La mujer sin piano [2009] y El muerto y ser feliz [2012]) realizadas a través de Lolita Films, la productora que él mismo creara en 1996 junto a Damián Paris y Lola Mayo, su coguionista habitual ("Javier Rebollo"). En términos generales, la obra de Rebollo se puede entender como un muestrario de desafíos formales y narrativos conducentes a una reafirmación del director como autor/creador. Sus películas se han visto así recompensadas con un gran reconocimiento crítico, así como con numerosos premios de prestigio en el circuito de festivales de cine de arte y ensayo tanto en el ámbito nacional como internacional (“Javier Rebollo").

En la tercera y última película de Rebollo, la coproducción hispanofranco-argentina El muerto y ser feliz (2012), Santos, un moribundo asesino a sueldo, inicia un viaje de Buenos Aires al norte de Argentina que adquiere progresivamente un carácter trascendente al ser un viaje de la vida a la muerte, de la civilización a la naturaleza, y, fundamentalmente, de la historia al mito. Durante la promoción de la película, el mismo Rebollo dio las claves para esta interpretación, señalando en varias ocasiones que la película tenía que ver con "la forja del mito" (en Ramón). Parece relevante, pues, explorar esta idea, mostrando con detalle cómo se articula en la película para hacer una interpretación global de la misma en términos de ese viaje "a la creación del mito" (Ramón) que pone en escena, y relacionar, a su vez, esta interpretación con la condición de Rebollo como autor y como ejemplo de la manera en que directores contemporáneos se reafirman como autores usando y subvirtiendo simultáneamente las convenciones genéricas y narrativas del cine clásico. En lo que sigue se va a argüir, por tanto, que en El muerto y ser feliz, la hibridez genérica, el uso consciente de una serie de géneros literarios y cinematográficos de larga raigambre, así como la puesta en escena de los 
mecanismos de construcción de un mito en el paso de una dimensión natural a otra sobrenatural o poética a través de la idea de viaje y a través, sobre todo, de un lenguaje cinematográfico fracturado-especialmente en la relación entre imagen y sonido y en la existencia de dos narradores en off que con su irónica palabra van construyendo y destruyendo, a veces simultáneamente, la historia de Santos que las imágenes muestran-le sirven a Rebollo como una manera de reafirmar su posición como auteur creador de mitos modernos en el panorama cinematográfico español e internacional actual.

En su seminal Lo sagrado y lo profano (1957), Mircea Eliade argumentó que los mitos cuentan historias sagradas que tuvieron lugar en el origen de los tiempos, en el tiempo primordial, siendo sus personajes dioses o seres sobrenaturales cuyas gestas constituyen misterios que el hombre no podría conocer si no le hubieran sido revelados (72). En ese sentido, "los mitos revelan, pues, la actividad creadora y develan la sacralidad (o simplemente la sobrenaturalidad) de sus obras. En suma, los mitos describen las diversas, y a veces dramáticas, irrupciones de lo sagrado (o de lo sobrenatural) en el Mundo" (72). Frente al mito, la leyenda típicamente es una narración historizada, en un contexto geográfico-temporal específico y protagonizada por seres humanos extraordinarios, que adquiere un carácter legendario a través de una tradición, "reflecting on a psychological level a symbolic representation of folk belief and collective experiences and serving as a reaffirmation of commonly held values of the group to whose tradition it belongs" (Tangherlini 385). Taipe Campos, a su vez, tras realizar un minucioso estudio comparativo de los diferentes acercamientos al mito, defiende que ni estos tienen que referirse siempre al origen del mundo, ni sus protagonistas deben ser siempre dioses, aunque sí tener características sobrenaturales, postulando la siguiente definición operativa: 
[E]I mito, en cuanto relato oral, es una práctica discursiva sobre los acontecimientos primigenios ocurridos en el principio de los tiempos, entre seres sobrenaturales, y que dan cuenta de la cosmogonía, de la antropogonía y del origen de algo en el mundo como los elementos naturales y los pertenecientes a los derivados de la naturaleza humana.

Aunque se podría argüir que lo que la película de Rebollo está poniendo en escena es la creación de una leyenda, al desarrollarse en un contexto geográfico e histórico precisos y al ser Santos un personaje "real" y no exhibir, en principio, características sobrenaturales, no se debe olvidar que la película no está presentando o desarrollando un mito, sino la creación discursiva del mismo. En otras palabras, Rebollo no parece estar interesado en el contenido del futuro mito creado alrededor de Santos, ni en el hecho de que Santos sea o no un ser sobrenatural-aunque las connotaciones religiosas de su nombre sean evidentes y haya claras indicaciones de que el personaje está precisamente en proceso de serlo-, sino en cómo a través de un "viaje", en un sentido literal (de Buenos Aires al norte de Argentina) y simbólico (de la vida a la muerte, de la historia lineal al tiempo sin fin del mito), y a través de la palabra que cuenta ese viaje, se va creando un mito que se instaura como tal una vez el personaje muere y llega a una dimensión que se presenta como trascendente en la película. Rebollo, en definitiva, está más preocupado por el proceso de transformación del personaje en una realidad poética o emblemática a través de una contradictoria palabra creadora que en el hecho de que la historia de Santos en algún momento posterior pueda ser categorizada, eventualmente, como mito, leyenda o incluso relato folclórico. En ese sentido, la historia desarrollada en El muerto y ser feliz parece presentar aspectos tanto del mito como de la leyenda. Se utilizará, pues, aquí el concepto mito en el mismo sentido no específico, como narrativa trascendente, en el cual Rebollo parece entenderlo, relacionándolo con algunas ideas que Eliade desarrolló al hablar de 
los mitos sagrados, algunas de las cuales, en realidad, también son pertinentes al hablar de la llamada leyenda.

El muerto y ser feliz comienza en un hospital de Buenos Aires con un Santos que es, en sus propias palabras, "una fábrica de tumores" (35:02-16). Pese a su deteriorada condición física, este español de Chinchón-como el propio José Sacristán (1937-), actor que lo interpreta-que ha pasado la mitad de su vida en Argentina, sigue aferrándose a la vida. Paradójicamente, a pesar de la discursividad que caracteriza una película como esta, cuya historia es desarrollada a través de una narración doble, no sabemos mucho del pasado de un personaje que apenas cuenta con diálogo, aunque sí de las consecuencias de este pasado en su presente: Santos es fundamentalmente un personaje solitario, un cowboy, un Quijote que acomete el último viaje de su vida cuando deja el hospital cargado de morfina robada para aliviar su dolor en su fiel y vieja montura, un coche al que llama Camborio, como el gitano del romance de García Lorca, y comienza un trayecto de la civilización a la naturaleza que resulta ser una aceptación de su propia mortalidad, condición indispensable en lo que parece ser su paso a la inmortalidad del mito. En el camino se encuentra con Érika (Roxana Blanco), una mujer que también huye, pero de su traumático pasado, y que a lo largo del viaje se convierte en su fiel escudero, compañera de aventuras primero, enfermera después y, finalmente, amante. En realidad, como el propio Rebollo ha apuntado, nunca estamos completamente seguros de si este viaje es real o una mera ensoñación del drogado Santos desde la cama de su hospital: "No me importa si se ve toda la película como un ensueño, me gusta esa idea. La idea arranca en el hospital, cierra los ojos como si ya estuviera muerto. Al final, hay un pestañeo y la película podría ser, por qué no, lo que sucede en ese pestañeo" ("El muerto y ser feliz es una película clásica”). De hecho, ni siquiera queda claro si Santos, que afirma haber sido "custodio" en el pasado y al que se presenta en la película como "un asesino a 
sueldo que no mata", es o ha sido, de hecho, un asesino, aunque hay indicios de que quizás fue un sicario paramilitar relacionado con la dictadura militar en Argentina, interpretación a la que apunta el hecho de que su destartalado Camborio es un Ford Falcon Rural De Luxe de 1976, un coche asociado con las estructuras represivas del poder en la dictadura militar argentina de los años 70 al tratarse de un vehículo similar al que utilizaban grupos paramilitares del gobierno para llevarse a los "desaparecidos" (Rebollo en "No busco que el espectador"). Según Rebollo: "Me gustaba tratar la idea de la muerte y un asesino. ¿Dónde está dicho que sea un matarife?... ¿Quién dice que no es una fantasía?... Aunque este personaje no haya matado, otros seguro que lo han hecho por él” ("El muerto y ser feliz es una película clásica”) (Fig. 1). Aunque Santos coincide en su viaje con personas de muy diferentes estratos sociales y es testigo de tensiones sociales, étnicas y económicas específicas de Argentina, a Rebollo no le interesa tanto el aspecto realista o social de este viaje, sino el aspecto simbólico tanto de la supuesta profesión de su personaje como de dicho viaje, aspectos ambos que aparecen articulados en la película a través de varios géneros que actúan como intermediarios necesarios entre realidad y ficción, como facilitadores, en definitiva, del viaje del tiempo lineal de la historia al tiempo cíclico de la naturaleza y el mito que la película pone en escena. 


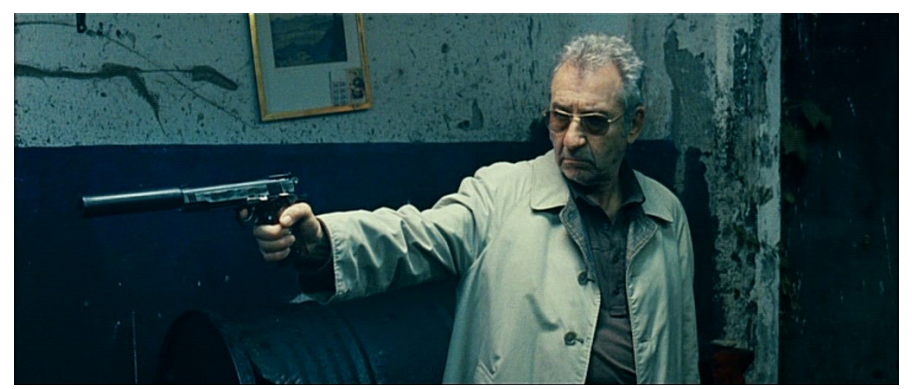

Fig. 1: Santos y su pistola (El muerto 14:48).

El muerto y ser feliz se promocionó como una "película de carretera, perros y pistolas", mostrando ya esa definición el carácter emblemático-mítico que Rebollo le quiere imprimir a su película a través de símbolos significativos que la emparentan con tradiciones genéricas específicas. De modo similar, todos los personajes, muchos de los cuales, además, no cuentan con un nombre propio, aparecen en la película o en los títulos de crédito finales con un apodo o frase que los emparenta, con frecuencia irónicamente, con diferentes tradiciones retórico-genéricas fácilmente reconocibles para un espectador cinéfilo: Santos, "un asesino a sueldo que no asesina"; Érika, "la chica que no parece la chica de una película"; "enfermera joven y bonita"; "policía viejo y curtido"; "una mujer que ayer fue rubia", etc. Cuando la película se estrenó, las críticas señalaron así su relación con un gran número de referentes literarios y cinematográficos, mostrando el carácter profundamente intertextual de una película construida no solo a través de la palabra de sus narradores, sino también mediante el uso consciente de una compleja red de referentes genéricos y culturales, lo cual se puede entender como un ejemplo de metarreferencialidad posmoderna, así como impronta de autor de Rebollo. Sin pretender ser exhaustivo, se señaló la filiación de la película con el relato crepuscular, especialmente en el ámbito de la novela negra y del western, con los llamados "films bardo", con el documental, así como con la obra de Aki Kaurismäki, François Truffaut, Juan Carlos Onetti, 
Sam Peckinpah, Samuel Beckett, Jorge Luis Borges y Miguel de Cervantes, con el Taller de Literatura Potencial Oulipo y con el posmodernismo literario, o incluso con películas específicas como El hombre que mató a Liberty Valance (John Ford 1962), Bombón: el perro (Carlos Sorín 2004) —cuyo guionista, Salvador Roselli, es también coguionista de la película de Rebollo-o Las acacias (Pablo Giorgelli 2011). De entre todos estos referentes, los géneros más comúnmente citados al hablar de la película fueron el de la road movie o película de carretera y el western o película del oeste. Penalva, por ejemplo, afirmó que "se trata de una propuesta bastante vanguardista que elimina las fronteras entre los géneros. Es, sobre todo, una road movie, pero pasada por el filtro del western, con toques de Godard y ecos de Hunter S. Thompson". También se mencionó a menudo la relación de la película con la novela de caballería y El Quijote. Lo que estos tres referentes genéricos tienen en común es el viaje, motivo que, como símbolo de transformación, ha estado presente en la cultura occidental desde la Odisea, si no antes. Así, según el cineasta Walter Salles, para el director Wim Wenders, uno de los grandes revitalizadores del género de la película de carretera en las últimas décadas, su origen "lay even further back in history-in our nomadic roots, in mankind's primal need to leave an account of its passage on earth" (68), lo que podría llevarnos incluso a la prehistoria y, de algún modo, relacionaría este género con estructuras primitivas de ritualización de la realidad, como modos de explicar la relación del hombre con su entorno, con el tiempo y consigo mismo, con los mitos, en definitiva. En términos cinematográficos, tanto el western como la road movie son géneros que han tenido un desarrollo particularmente importante en la tradición de Hollywood, pues ambos se imbrican en el engranaje del sueño americano y su idea de movilidad social. Así, con respecto al western, García Ochoa defiende: “En el cine norteamericano, la estructura narrativa en torno al desplazamiento tiene un primer desarrollo en el Western, género histórico consagrado a poner en imágenes el proceso de colonización del país" (191). Eyerman y Löfgren, a su 
vez, defienden que las películas de carretera "articulate particular values and longings that have resonated with audiences around the world, but particularly those in the United States... This resonance has its basis in the ways freedom and social mobility have been linked to physical mobility as themes in North American culture, or at least that part of it which Hollywood has attempted to represent" (54). La tradición europea de las road movies, sin embargo, no se puede entender tan solo como un ejemplo de colonización cultural, sobre todo si tenemos en cuenta que la novela de caballería vía El Quijote, al igual que la picaresca, también pueden considerarse antecedentes de la novela y película de carretera modernas (Pérez 17). Esto es así no solo porque en ambos géneros literarios sea decisiva la idea del viaje, sino porque dicho viaje, de nuevo, tiene un carácter marcadamente simbólico, al igual que ocurre en la película de carretera, cuyo desarrollo "suele responder a la transformación paulatina que experimentan uno o más personajes en el transcurso de su desplazamiento por espacios físicos, humanos y sociales que suponen vivencias decisivas para la existencia de esos personajes" (Sánchez). En ese sentido, como han señalado Mazierska y Rascaroli, los directores de las road movietanto en EEUU como en Europa- "use the motif of the journey as a vehicle for investigating metaphysical questions on the meaning and purpose of life. Travel, thus, commonly becomes an opportunity for exploration, discovery and transformation (of landscapes, of situations and of identity)" (4).

Cabe destacar que Rebollo no solo articula su película a través de diferentes géneros, sino que, además, hace una relectura consciente de estos, especialmente del género de la road movie. En sus propias palabras, “[h]oy en día los géneros no existen, salvo que quieras hacer un cine imitación de un cine de otra época con lo cual no haces cines, sino haces maquetas, pastiches. Al género hay que hacerle algo, hay que darle una vuelta... Contar lo mismo, pero de otra manera" (Casa de América: 00:11-26). Así, El muerto y ser felizuna película con dos personajes principales a los cuales "[l]o único que parece 
importarles es seguir en movimiento" (Trueba 58) - contiene muchos de los elementos característicos de las road movies: la carretera, el coche (modo de transporte mecánico), las paradas (áreas de descanso, gasolineras, moteles, casas de campo, balnearios...), la idea de movimiento que le da a la película un ritmo cadencioso y potencialmente simbólico, los encuentros inesperados, la presencia del paisaje como elemento físico, pero también espiritual, así como la idea de un viaje que enfrenta al personaje con una nueva realidad muchas veces más interna que externa-en este caso esa nueva realidad es, paradójicamente, la muerte (Fig. 2). Santos y Érika se encuentran en una estación de servicio y, en su viaje, ambos pasan por moteles, hoteles, balnearios, casas de campo, etc., paradas literales y semióticas que puntúan un texto marcadamente autoconsciente en un género ya de por sí de marcado carácter reflexivo (Morris). La variada geografía argentina y los diferentes tipos sociales con los que ambos se van encontrando marcan un viaje discontinuo de 6000 kilómetros por Buenos Aires, Rosario, Santa Fe, Córdoba, Santiago del Estero, San Miguel de Tucumán, Salta, Jujuy y Bolivia, convirtiéndose el paisaje en un personaje más, quizás el más importante. El propio Rebollo ha declarado que la inmensidad del paisaje argentino, las largas distancias entre sus pueblos y ciudades, así como la existencia de pocas autopistas, fueron los aspectos que le llevaron a cambiar su idea inicial de rodar la película en Europa: "Cuando haces una road movie necesitas esas distancias grandes, ese paisaje que cambia tanto. También está el surrealismo de Argentina, que es un país muy absurdo y extraño" ("El muerto y ser feliz es una película clásica”). En el viaje de Santos y Érika, además, espacio y tiempo se confunden al atravesar ambos una Argentina "donde conviven los tipos más enraizados y atávicos del país con la modernidad de la capital" (Vidal Sanz), es decir, donde conviven diferentes estadios de la historia del país, diferentes Argentinas. 


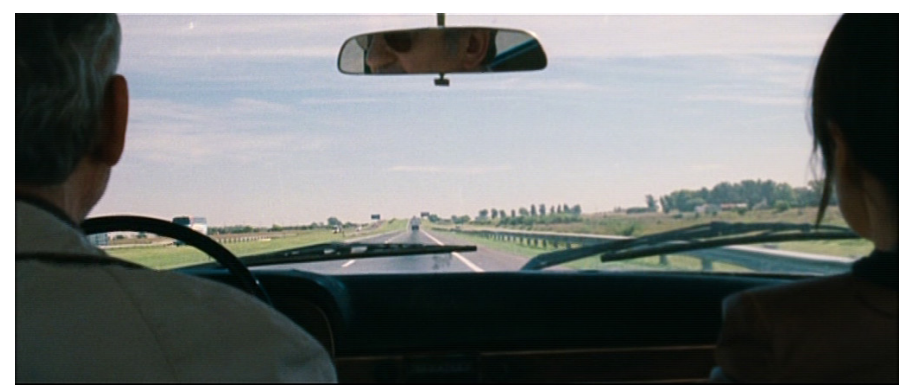

Fig. 2: Santos, Érika y Camborio en la carretera (El muerto 19:28).

A lo largo de este trayecto parece que Santos acepta su historia y su propia mortalidad precisamente al experimentar la historia de Argentina en su dimensión más cotidiana, casi en su aspecto intrahistórico, a través de diferentes paisajes, diferentes estratos sociales e incluso diferentes "tiempos", hasta Ilegar a una naturaleza salvaje en la que finalmente "muere"; hasta llegar a un "no tiempo" en el que el personaje y la naturaleza-simbolizada en una serie de animales salvajes de inquietante presencia-terminan fundiéndose en lo que parece ser la eternidad del mito. En ese sentido, en El muerto y ser feliz, la fusión implícita entre hombre y paisaje característica del género se hace explícita como consecuencia directa del mito creado en su diégesis y de la introducción de la palabra oral que lo constituye como tal. El viaje de Santos, en definitiva, no es solo un viaje al norte de Argentina, sino un viaje a un fin que es también inicio, del tiempo lineal de la historia al tiempo cíclico de la naturaleza, el cual, según muchos estudiosos, es también el tiempo del mito (Taipe Campos 7-13). En este viaje, pasado, presente y futuro se confunden y superponen en la suspensión temporal que implica la estructura mítica, la cual, para Mircea Eliade implica siempre el paso del tiempo profano o lineal al tiempo sagrado, en el que "la muerte viene a considerarse como la suprema iniciación, como el comienzo de una nueva experiencia espiritual" (143-44), 
como una forma de regeneración de uno mismo y, por ende, del mundo. En la apertura al mito que El muerto y ser feliz pone en escena, la película de carretera, un género por naturaleza autorreflexivo, se convierte en modo de articulación ideal para un proceso de indeterminación temporal, pues, como ha señalado Corrigan, a través del movimiento del coche, "time on the road becomes figurative space", puesto que "the road movie embodies the endless potential of future space, outer space, and a past that is continually fleeing" (146).

Este viaje de Santos a su muerte-viaje caracterizado por la libertad que le da la conciencia de esa inminente muerte, así como por el estado mental narcotizado que le produce la morfina que toma para el dolor-es paralelo a un proceso de fractura de las convenciones cinematográficas del cine clásico en general y del género de la road movie en particular. En ese sentido, la creciente decadencia física del personaje durante este viaje, su muerte (literal o metafórica) y la "superación" de esa muerte—y del tiempo lineal一, a través de un proceso de eternización trascendente, es paralela a la deconstrucción del lenguaje cinematográfico clásico en la película en un intento de develar los mecanismos de creación narrativos del mito, pero también de crear una retórica de la imagen cinematográfica desnaturalizada y basada en la contradicción y el sentido múltiple frente al lenguaje convencional y en principio unívoco de los géneros clásicos. Cabe destacar que esta desnaturalización comienza ya en la elección de actores; así, si tenemos en cuenta la importancia que en las interpretaciones de José Sacristán siempre han tenido su entonación y característica voz grave, la falta de diálogos de su personaje en la película es un recurso profundamente distanciador para el espectador español y latinoamericano. Según Trueba, el uso que Rebollo hace de Sacristán y otros actores muy conocidos, como Carmen Machi en La mujer sin piano, es una manera de "aprovechar la imagen que estos actores proyectan para someterlos a un proceso de desnaturalización constante, jugando con sus estereotipos 
para luego desubicarlos..." (58). En términos ya puramente cinematográficos, si en su filmografía anterior, buscando evitar la identificación del espectador, Rebollo jugaba con la imagen, haciendo que esta nunca alcanzara a mostrar del todo lo que estaba sucediendo o sencillamente haciendo que no mostrara lo que se estaba escuchando, aquí, Rebollo lleva la ruptura del lenguaje cinematográfico mucho más lejos, haciendo del visionado de la película una experiencia desafiante para el espectador y conduciendo la misma película casi al borde de su destrucción, aunque siempre manteniéndose firme detrás de ella. En términos de cinematografía, una característica que el director ya había desarrollado en sus películas anteriores, especialmente en La mujer sin piano (2009), se repite aquí: la cámara que se aleja de la escena principal o que sencillamente parece retrasarse al no estar sincronizada con el movimiento de los personajes, los cuales a veces están "de espaldas a cámara o directamente fuera de cuadro" (Trueba 58). Además de rodar cuando pudo una o dos tomas por plano para captar los gestos en movimiento (Vidal Sanz), Rebollo también filmó en 16 mm con una cámara fácil de manejar, trabajando después con la densidad para producir "una especie de polvo en la imagen, generando una idea de movimiento e imperfección" (Vidal Sanz) y dándole así a la película un aspecto naturalista, casi documental.

La deconstrucción del lenguaje fílmico clásico en la película se produce, sobre todo, en el campo del sonido y, especialmente, en la relación entre sonido e imagen, lo cual afecta profundamente el punto de vista, tanto de la misma narración como del espectador que intenta (re)construir esta narración. Así, "[l]a película está plagada de planos surrealistas llenos de simbolismo, arropados por unas tomas de sonido hiperrealistas, con varias fuentes superpuestas, ganando cada una su espacio según le interesa a la trama narrativa, como la machacona lista de nombres que Santos repite "en off" y que parecen ser las personas que ha matado" ("El muerto y ser feliz, cine de vanguardia”). En ocasiones, los sonidos (incluyendo ciertos diálogos) 
no se corresponden con lo que vemos en pantalla; en otras, se adelantan, se retrasan, se superponen o incluso desaparecen con respecto a las imágenes, viéndose escenas en movimiento sin ningún sonido ambiente. Sin embargo, el aspecto que más reacciones encontradas produjo entre crítica y público fue la existencia de dos narradores extradiegéticos en off (con la voz de dos de los guionistas de la película, Lola Mayo y el propio Rebollo), que van construyendo y deconstruyendo con una entonación hierática y monótona la historia del viaje de Santos y Érika a medida que este se desarrolla, a veces sencillamente repitiendo lo que muestran las imágenes o lo que se dice en los diálogos, a veces anunciando o incluso contradiciendo ambos; en ocasiones expresándose de un modo esquemático, casi como si estuvieran leyendo anotaciones del guion, y en otras, con un lenguaje detallado y lleno de florituras literarias a modo de narradores decimonónicos. Al principio de la película nos encontramos con una voz femenina aparentemente objetiva que anuncia lo que el espectador va a ver o cuenta lo que este está viendo, pero pronto esta voz se revela como subjetiva cuando se produce la sospecha de que no sabe todo lo que está ocurriendo o no conoce bien los detalles de la historia de Santos; aparece entonces una segunda voz masculina que primero se alterna con la primera y que finalmente aparece casi en competición con esta, multiplicándose las interpretaciones de la historia contada mientras se cuenta, entrando de este modo, según Rebollo, "en el territorio de las voces múltiples y el mito" (Ramón). En este juego de deconstrucción de los esquemas narrativos del cine clásico, se debe destacar, en primer lugar, que la existencia de una narradora femenina, así como el hecho de que con frecuencia sea el punto de vista de Érika aquel con el que se identifica el espectador, se puede entender también como una deconstrucción del punto de vista hegemónico tradicional en el aparato cinematográfico del cine clásico, en el que, tal como mostrara Mulvey en sus influyentes ensayos "Visual Pleasures and Narrative Cinema" y "Afterthoughts on 'Visual Pleasure and Narrative Cinema' Inspired by King Vidor's Duel in the 
Sun (1946)", la mujer siempre era el objeto de deseo pasivo de una mirada voyerista o fetichista (implícitamente) masculina que determinaba el punto de vista del espectador. En ese sentido, el género de la película de carretera es un medio ideal para este tipo de deconstrucción del punto de vista, pues, como ha señalado García Ochoa, siguiendo a Corrigan, su carácter autorreflexivo lo convierte en un género que "reflexiona sobre los mecanismos que construyen el punto de vista en un medio (el cine) históricamente patriarcal” (189190). Además, en segundo lugar, la importancia de la presencia de estos dos narradores se manifiesta en que la película se hace tal en la primera escena a través no de lo que vemos, sino de lo que escuchamos por boca de la primera narradora, esto es, a través de la palabra, que nos introduce en el mundo ficcional al mismo tiempo que, simultáneamente, lo crea. Así, vemos un plano general picado de una plaza de Buenos Aires e inmediatamente después escuchamos la voz de la narradora introduciendo a Santos, al que se describe con cierto detalle, aunque todavía no lo podemos distinguir en la imagen (Fig. 3). Inmediatamente la cámara va descendiendo y vemos al personaje tal como acaba de ser descrito. Desde el comienzo, por tanto, lo visto y lo escuchado-y lo escuchado en este caso no es solo el diálogo y ni siquiera este es el sonido principal-, aparecen al mismo nivel, complementándose, pero también en ocasiones compitiendo y contradiciéndose. En otros momentos lo que una de las voces dice se superpone a lo que está pasando y no escuchamos el diálogo, sino la paráfrasis narrativa de este diálogo. También hay varios casos en que uno de los narradores cuenta lo que los personajes van a decir e inmediatamente escuchamos dicho diálogo con las mismas palabras. Como ejemplo de la clara ironía con la que en muchas ocasiones se trata este recurso, tenemos también momentos en que la voz narrativa interactúa con los diálogos de los personajes; así ocurre cuando Érika, después de que Santos esnifa cocaína dentro del coche para aliviar su dolor, le dice que tiene que descansar y, mientras la cámara se mueve hacia un convento cercano, se 
oye a una de las voces narrativas decir: "Amén" (1:04:54-1:05:12). Los casos más interesantes, sin embargo, se producen cuando una de las voces en off remarca lo ambiguo de algunos detalles de la historia, poniendo en cuestión la veracidad de la narración misma: "Que fue en Tucumán, seguro. Que en la calle Gobernación y en el Hotel Astoria, también. Y es probable que de lo que pasó en la habitación después, Santos no recordará nada. Solo Érika y unos pocos han podido contarlo" (1:02:50-1:03:01). O cuando contradice lo que estamos viendo (cuando afirma que un balneario está lleno de niños y la escena lo muestra lleno de gente anciana) o incluso lo que acaba de decir (cuando dice que Santos es muy impaciente, para decir poco después que es muy paciente). Los ejemplos son múltiples y muy variados, apuntando todos a una construcción y deconstrucción simultáneas del mundo creado en la película mediante la voz de estos narradores que van creando el mundo ficcional y fisurándolo al mismo tiempo, abriéndolo a las múltiples interpretaciones, a las múltiples perspectivas, algunas contradictorias, del mito. En varias ocasiones durante la promoción de la película, Rebollo recalcó que la voz, lo oral, a través del romance de ciego, a través de la balada norteamericana o a través del Cantar de gesta francés, tenía siempre que ver con el mito: "Ese mito también lo crean las palabras cuando se oyen cosas como 'se cuenta, se dice que sucedió tal cosa'; esa anticipación aporta una riqueza porque las palabras también son imagen" ("El muerto y ser feliz es una película clásica”). Ese "se cuenta", además, apunta también al hecho de que, como mostró Eliade, los mitos no se presentan con una autoría, pues “[d]esde el instante en que son percibidos como mitos, sea cual haya sido su origen real, no existen más que encarnados en una tradición oral colectiva" (Taipe Campos 5). El mito de Santos tiene que ver así con la carretera, con el viaje, pero también con la oralidad y con la palabra dicha colectivamente, con ese (re)crear la realidad y (re)crearse a uno mismo mientras se cuenta una historia llena de múltiples interpretaciones, contradicciones y elipsis. 


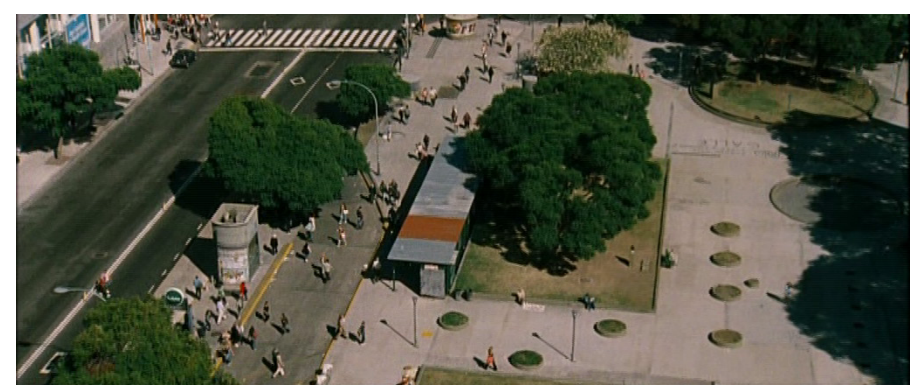

Fig. 3: "Media mañana en esta gran plaza del centro de Buenos Aires" (El muerto 01:16).

Después de muchas peripecias, cuando Santos y Érika llegan a la casa de la familia de esta en Salta llegan también al destino simbólico de su viaje: la muerte para él, condición para su paso a una realidad trascendente, y la vuelta al origen, a la familia, para ella. No es casual que Érika le cuente entonces a Santos la historia de un perro, Walter, que tiempo atrás ella ayudó a liberar y que desde entonces vaga por las montañas inseminando a todas las perras con las que se encuentra. El perro y las múltiples historias creadas a su alrededor, contradictorias y exageradas, son parte de un mito local como ya lo está llegando a ser el mismo Santos. Para el nacimiento definitivo del mito de Santos, sin embargo, debe desaparecer el ser humano, pues el mito no solo se construye en la palabra, en una palabra, además, hiperbólica y paradójica como la que caracteriza la narración, sino que, además, siempre crece en la memoria, no en el presente (Vidal Sanz). En una memoria, además, colectiva, aunque, del mismo modo que Rebollo no parece estar interesado en el contenido específico del mito de Santos una vez se constituye, tampoco parece estar interesado en la naturaleza concreta de esa memoria colectiva que ayuda a su (re)creación, aunque resulta tentador decir que quizás esa colectividad que este mito presupone la constituyen, precisamente, los espectadores de la película, los cuales, a modo de ritual, reviven, si no el mito, sí la construcción 
del mismo que la película pone en escena. En algún momento, este perro aparece en los alrededores de la casa y, tras conseguir huir una vez más de la persecución de la familia y de los criados del padre de Érika, que quieren matarlo para que deje de reproducirse, entra en la habitación de Santos, al que mira fijamente. Tras ese momento de reconocimiento, Santos se monta en Camborio y deja la casa. El narrador masculino dice entonces, recalcando la identificación entre Santos y Walter: "Y aunque nadie lo vio, y en esto no han sabido ponerse de acuerdo, dicen que Santos se fue entonces. De dónde sacó las fuerzas, si es que las tuvo, no se sabe. De Walter, aquel bello animal, nunca más se supo" (1:16:37-52). Las dos voces narrativas, a modo de polifonía orquestal, nos cuentan entonces dos posibles finales de la historia de Santos y Camborio. En ambos, Santos llega al pie de la cordillera, deja a Camborio y se adentra en la selva, un espacio tradicionalmente mítico, buscando la conexión con la naturaleza, con su animalidad, con la oralidad, más allá de la racionalidad y en busca de lo que Rebollo parece entender como el mito y su universo simbólico. Se ve a Santos tirado y su voz, de fondo, confundida y casi en comunión con los sonidos de la selva, repitiendo, a modo de letanía, unos versos altamente significativos: “¿Es de noche o es de día? / ¿Córdoba o mi cuarto del hospital? / ¿Qué hora es? / Si no fuera obligatorio pensar, / poder quedarme en blanco, / volver a la carretera... / sin pensamientos, sin sueños. / No rezo ni me arrodillo, / estoy en condiciones de pelear" (1:17:50-1:18:05) Santos, como un nuevo Quijote, pasa la noche en la selva, la cual habla con él "de otra manera" (1:18:06-11). En ese momento, las dos voces narrativas se superponen al contar lo que ocurrió después, resaltando ambas el proceso de animalización que Santos sufre, proceso en el que este, además, parece perder su capacidad verbal. Así, la voz femenina dice: 
Y amanece de nuevo sobre el cuerpo de Santos, encogido como un animal herido. Delirando. Silba bajito. Mueve los labios como si soñara. Una tortuga grande y vieja, sabia, un sapo a punto de hibernar y un caballo blanco miran fijamente a Santos invitándole a permanecer allí. (1:18:33-51)

Mientras que la voz masculina comenta:

Y aquella noche Santos escuchó el tañido de una campana donde no había campanas. Y soñó con caballos. Caballos salvajes de las montañas que nunca habían visto un hombre y que no sabían nada de Santos ni de su vida y en cuyas almas Santos llegaría a vivir para siempre. (1:18:34-52)

Inmediatamente después, se dan dos versiones del "final" de Santos, una en la que este muere en la selva y su cuerpo sin identificar lo encuentra un pescador mucho tiempo después, siendo llevado a la morgue del hospital de San Pablo en Salta, y otra en la que Santos se levanta, se arrastra y desanda el camino hasta Camborio, que "le ha esperado fiel con la puerta abierta", cabalgando juntos "para siempre, forajidos libres y valientes sin culpa ni pecado cruzando fuertes y fronteras, sumando kilómetros. Dicen que inmortales" (1:19:201:20:16). Se ve entonces la carretera en movimiento, un pueblo, campesinos, y se escucha música tradicional de fondo y una canción en lengua indígena sobre un bandido boliviano, "Cabalga, Camborio, cabalga", compuesta por el mismo director y su hermano, el director de arte Miguel Ángel Rebollo. En esta canción, que asocia a Santos con la mítica figura del bandido ("un pistolero muerto que viaja más allá de la frontera") y que inserta su recuerdo en una colectividad no definida que hiperboliza su figura (" $i$ Cien muertos y sin culpas! ¡Cien fernets y sin resaca!"), se insta a este a morir y a descansar ("¡Hay que morir! ¡Y descansar!") (1:20:25-1:22:01) (Fig. 4). 


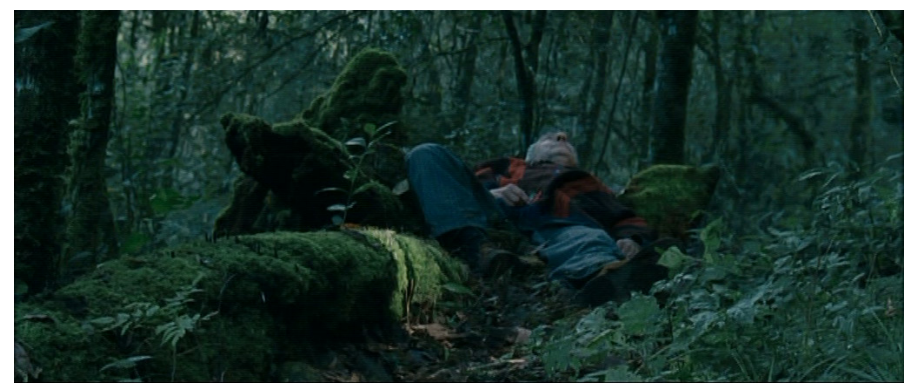

Fig. 4: Noche en la selva (EI muerto 1:18:13).

Tras esa noche en la selva y su muerte/desaparición, Santos parece pasar a un plano trascendente donde no será olvidado. Se ve el coche primero avanzando por la carretera con Santos conduciéndolo, e inmediatamente después, abandonado al borde del bosque. El final realista y el mítico aparecen entrelazados así a un nivel puramente visual, el tiempo histórico y el tiempo cíclico combinados. En la última escena, a modo de coda, vemos a Santos comiendo un helado dentro de Camborio, como un niño, ansioso, "muerto y feliz", el fin uniéndose al comienzo, el tiempo de la naturaleza, eternamente repetido, superponiéndose al tiempo lineal, casi como un tiempo en espiral, un tiempo finalmente suspendido (Taipe Campos 13), mientras se escucha la canción "Noches árticas" de Nacho Vegas (Fig.5). Érika, trasunto del espectador, observa este momento de plenitud, sonriente, desde el asiento trasero (Fig. 6). En ese momento la transformación de Santos en mito ya es completa. La película pone así en escena la construcción del mito de Santos, develando precisamente el proceso de construcción a través de un discurso oral en el que no faltan las hipérboles, los elementos mágicos y folclóricos, las diferentes versiones sobre algunos de sus eventos (incluyendo el final), así como el proceso de animalización de su personaje al "morir", al abandonar su mundo y adentrarse en el mundo de la naturaleza en ese rito de pasaje que 
parece ser la noche en la selva. Y aquí la película tiene que terminar, pues puede poner en escena el proceso de construcción narrativa de un mito a través de un lenguaje cinematográfico fracturado, pero no puede ir mucho más allá de esa profunda ruptura formal sin quedar condenada al silencio.

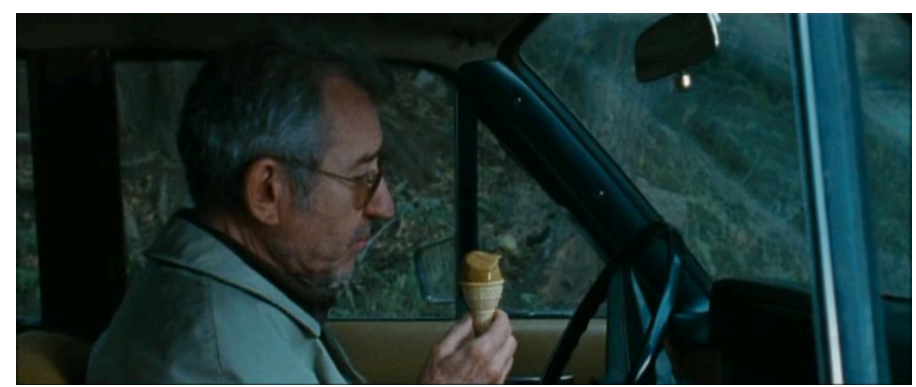

Fig. 5: Santos comiendo un helado (El muerto 1:24:15).

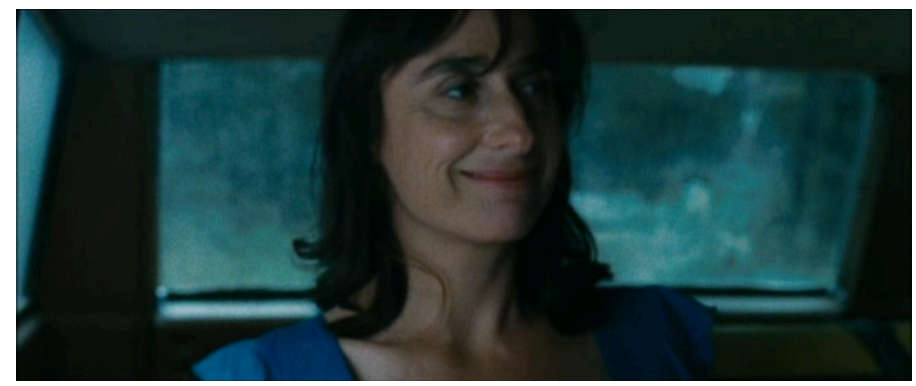

Fig. 6: Érika sonriendo (El muerto 1:18:15).

Según Rebollo, El muerto y ser feliz "es una película clásica hecha por un moderno, es un intento deliberadamente fallido de alcanzar un clasicismo que en realidad no quiero, pero con el que juego todo el rato" ("El muerto y ser feliz es una película clásica”). Rebollo parece entender por "clasicismo" el hecho 
de desarrollar géneros clásicos con un esquema narrativo tradicional y por “modernidad" la deconstrucción de aquellos en la hibridez y el uso consciente de los mismos, en los juegos con el punto de vista y en la ruptura del lenguaje cinematográfico clásico. Su película, por tanto, es una película clásica hecha por un director "moderno" en un juego de autor que, se podría añadir, parece un ejercicio de estilo posmoderno, casi de pastiche, lo que sitúa al director y su película en la misma encrucijada pasado/presente/futuro en la que sitúa a su personaje principal. A esta interpretación apuntaría también el hecho de que a Rebollo no le parece interesar, estrictamente hablando, el contenido del mito ni su relevancia social, sino el proceso por el cual este se crea discursivamente en una palabra múltiple, polisémica y contradictoria, detrás de la cual, paradójicamente, se encuentra siempre él mismo y su palabra de autor. Del mismo modo que Rebollo crea una canción de aire popular en lengua indígena, también juega a construir un mito tradicional, pero el mito de El muerto y ser feliz, frente a aquel, oral y colectivo, lo tiene a él como creador absoluto y principal intérprete. En un momento en el que las fronteras entre el cine de género y el llamado cine de autor son cada vez más porosas y en el que la idea de autor como punto de origen del significado de una película es cada vez más difícil de mantener, Rebollo le pone "pruebas al infinito para ver si resiste" (Juarroz 395) jugando con las convenciones narrativas y de género en un proceso de deconstrucción y desnaturalización de estas que termina siendo, simultáneamente, una reafirmación de su poder como director en la creación de un paradójico mito de autor. 


\section{Obras citadas}

Casa de América. “El muerto y ser feliz, Javier Rebollo”. YouTube, 25 abr. 2013, www. youtube.com/watch?v=N5zFJM8_8Mc.

Corrigan, Timothy. A Cinema Without Walls: Movies and Culture after Vietnam. Rutgers UP, 1991.

Davies, Anne. "Introduction: The Study of Contemporary Spanish Cinema". Spain on Screen: Contemporary Developments of Spanish Cinema, editado por Anne Davies, Palgrave McMillan, 2011, pp. 1-18.

Eliade, Mircea. Lo sagrado y lo profano. Paidós, 1998.

Eyerman, Ron, y Orvar Löfgren. "Romancing the Road: Road Movies and Images of Mobility”. Theory, Culture \& Society, vol. 12, 1995, pp. 53-79.

García Ochoa, Santiago. “Algunas notas sobre la aplicación de la categoría de género cinematográfico a la Road Movie”. Liño: Revista Anual de Historia del Arte, vol. 15, 2009, pp. 187-196.

“Goya.-Almodóvar, mejor dirección, pide 'protección de Estado' para el cine de autor: 'Está en serias vías de extinción.'” La Vanguardia, La Vanguardia Ediciones, 26 ene 2020, www.lavanguardia.com/vida/20200126/473134113460/goya--almodovarmejor-direccion-pide-proteccion-de-estado-para-el-cine-de-autor-esta-en-seriasvias-de-extincion.html.

Gubern, Román, et al. Historia del cine español. Cátedra, 2009.

“Javier Rebollo". The Internet Movie Database, IMBD.com, Inc, n.d., www.imdb.com/ name/nm1503559/.

Jeong, Seung-hoon, y Jeremi Szaniawski. “Introduction”. The Global Auteur: The Politics of Authorship in $21^{\text {st }}$ Century Cinema, editado por Seung-hoon Jeong y Jeremi Szaniawski, Bloomsbury Academic, 2017, pp. 1-19.

Jordan, Barry, y Mark Allinson. Spanish Cinema: A Student's Guide. Hodder Arnold, 2005.

Juarroz, Roberto. "Séptima poesía vertical. 112". Poesía vertical: Tomo I, Emecé editores, 2005, p. 395.

Mazierska, Ewa, y Laura Rascaroli. Crossing New Europe: Postmodern Travel and the European Road Movie. Wallflower P, 2006.

“Modo de representación institucional (M.R.I.)". Análisis fílmico. Repositorio de recursos filmicos, www.analisisfilmico.uji.es/web/modo-de-representacioninstitucional-m-r-i|. 
Morris, Christopher. "The Reflexivity of the Road Film". Film Criticism, vol. 28, no. 1, Fall 2003, pp. 24-52.

Mulvey, Laura. "Visual Pleasure and Narrative Cinema". Screen, vol. 16, no. 3, Autumn 1975, pp. 6-18.

-. "Afterthoughts on 'Visual Pleasure and Narrative Cinema' Inspired by King Vidor's Duel in the Sun (1946)". Framework: The Journal of Cinema and Media, no. 15/17, 1981, pp. 12-15.

El muerto y ser feliz. Dirigido por Javier Rebollo. Actores José Sacristán, Roxana Blanco, Splendor Films, 2012, DVD.

"El muerto y ser feliz, cine de vanguardia por el que hay que luchar". eldiario.es, Eldiario.es, 3 ene. 2013, www.eldiario.es/politica/muerto-feliz-cine-vanguardialuchar 0 86441726.html.

Penalva, Joaquín Juan. "La leyenda de Santos y Camborio". El espectador imaginario, Aula Crítica: Escuela de Crítica Cinematográfica, vol. 42, may. 2013, www. elespectadorimaginario.com/el-muerto-ser-feliz/.

Pérez, Jorge. Cultural Roundabouts: Spanish Films and Novel on the Road. Bucknell UP, 2011.

Ramón, Esteban. "Javier Rebollo viaja a la creación del mito en El muerto y ser feliz." RTVE: Noticias, ene 2013, www.rtve.es/noticias/20130103/javier-rebollo-viajacreacion-del-mito-muerto-ser-feliz/595066.shtml.

Rebollo, Javier. "No busco que el espectador se identifique con mis personajes". Entrevistado por Fernando G. Varea. Espacio Cine, Wordpress.com, 23 nov. 2012, www.espaciocine.wordpress.com/2012/11/23/javier-rebollo/.

-. "El muerto y ser feliz es una película clásica hecha por un moderno". Entrevistado por Juan Sardá, El Cultural: El Mundo, Unidad Editorial, S.A., 10 ene. 2013, www. elcultural.com/noticias/buenos-dias/Javier-Rebollo/4241.

Salles, Walter. "Notes for a Theory of the Road Movie". New York Times Magazine, 11 nov. 2007, pp. 66-70.

Sánchez, S. "El muerto y ser feliz: Carretera y manta”. Cultura: La Razón, Audiovisual Española S.A., 11 ene. 2013, www.larazon.es/el-muerto-y-ser-feliz-carretera-ymanta-FY652272. 
Taipe Campos, Néstor G. "Los mitos: Consensos, aproximaciones y distanciamientos teóricos". Gazeta de antropología, no. 20, art. 16, 2004, http://www.ugr. es/ pwlac/G20 16NestorGodofredo Taipe Campos.pdf.

Tangherlini, Timothy R. "It Happened Not Too Far From Here... : A Survey of Legend Theory and Characterization”. Western Folklore, vol. 49, no. 4, oct. 1990, pp. 37190.

Triana-Toribio, Nuria. "Auteurism and Commerce in Contemporary Spanish Cinema: Directores mediáticos”. Screen, vol. 49, 2008, pp. 259-76.

Trueba, Jonás. "El viaje vertical. Javier Rebollo filma en Argentina El muerto y ser feliz". Cahiers du cinéma: España, vol. 47, julio-agosto 2011, pp. 57-59.

Vidal Sanz, Rafael. "El muerto y ser feliz: el héroe moderno es siempre una paradoja”. Extracine, Hipertextual, 2 mar. 2013, www.extracine.com/2013/03/critica-de-elmuerto-y-ser-feliz. 